\title{
A Short Review on the Morphology of Trypanosoma cruzi: from 1909 to 1999
}

\author{
Wanderley de Souza \\ Laboratório de Ultraestrutura Celular Hertha Meyer, Instituto de Biofísica Carlos Chagas Filho, Universidade \\ Federal do Rio de Janeiro, CCS-Bloco G, 21941-900 Rio de Janeiro, RJ, Brasil
}

The morphology of Trypanosoma cruzi is reviewed since the initial description of Giemsa-stained preparations by Carlos Chagas until the most recent micrographs obtained with freeze-fracture techniques. Special emphasis is given to structures such as the cell surface, the flagellum, the kinetoplast, the reservosomes and the endocytic pathway, and the acidocalcisomes.

Key words: Trypanosoma cruzi - fine structure - cell surface - flagellum - kinetoplast - reservosome acidocalcisome

The description of Trypanosoma cruzi in 1909 by Chagas was the beginning of a new phase of the biomedical sciences in Brazil. Looking at the present it is clear that in addition to the intrinsic importance of $T$. cruzi as the agent of a disease with a high prevalence, this protozoan, as well as other members of the Trypanosomatidae family, became important models for the study of basic biological questions. Indeed, a large number of Brazilian scientists dedicated most of their time in the study of these protozoa, introducing new methodologies which were later on used to study other problems. In relation to the application of electron microscopy in biomedical sciences it is clear that modern techniques such as freeze-fracture, cytochemistry, immunocytochemistry, three-dimensional reconstruction, microanalysis, etc. were first introduced in our country to the study of trypanosomatids.

\section{THE FIRST IMAGES}

The first study on the morphology of $T$. cruzi was made by Carlos Chagas. I had no access to the original material. However, looking the illustrations published in the first paper (Chagas 1909), it is clear that the author obtained excellent preparations of Giemsa-stained samples (Fig. 1). Structures such as the nucleus, the blepharoplast (presently known as kinetoplast), and the flagellum can be easily recognized. The quality of the illustrations is probably due to the fact that at that time the most important protozoologists, including Giemsa, Hartman and Prowaseck, worked for some

Fax: +55-21-260.2364. E-mail: wsouza@ biof.ufrj.br Received 9 June 1999

Accepted 9 August 1999 time at the Instituto Oswaldo Cruz. During the next 40 years the obtained images were basically identical to those reported in the original paper. Fig. 2 shows images of trypomastigote, amastigote and epimastigote forms of $T$. cruzi.

\section{THE OBSERVATION OF WHOLE CELLS}

The first images of $T$. cruzi using the electron microscope was obtained by Hertha Meyer and Keith Porter in 1950 and published in 1954 (Meyer \& Porter 1954). At that time it was impossible to obtain sections thin enough to be observed in the electron microscope. The authors allowed epimastigote and trypomastigote forms to adhere to copper grids previously coated with formvar, let them do dry and observed in the electron microscope. The parasite was to thick to be observed in a microscope operating at $60 \mathrm{kV}$, so that no information could be obtained about the inner portion of the cell. However, evidences were obtained about the existance of filamentous structures located at the cell periphery, then designated as the periplast (Fig. 3). It was also shown that treatment of the cells with trypsin eliminated the fibrilar structures, thus indicating their proteic nature. At present we know that the authors was describing which now days is recognized as the sub-pellicular microtubules.

In 1978 similar preparations were examined in a high voltage electron microscope, operating at $1000 \mathrm{kV}$. It was then possible to obtain new information on the kinetoplast, the association of the flagellum with the cell body, and the identification of other cytoplasmic structures (Fig. 4). In addition, the presence of only one, and highly ramified, mitochondrion per cell could be confirmed. More recently similar preparations have been examined with more modern microscopes, making it possible to visualize new organelles, such as the 


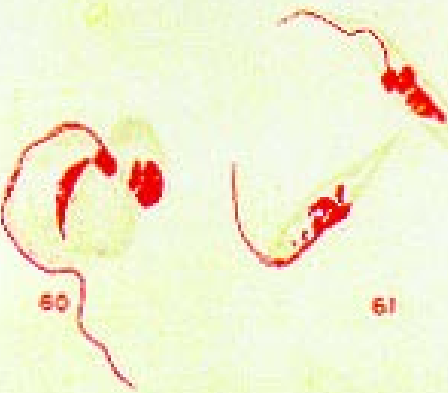

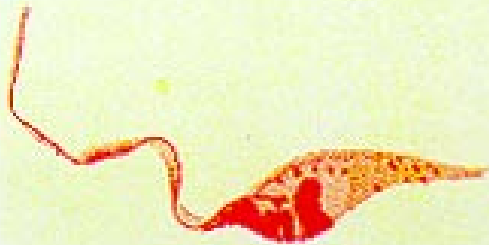

65

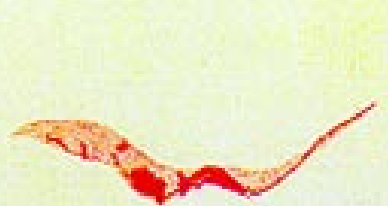

66

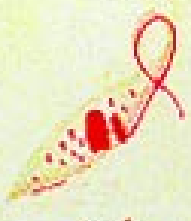

67

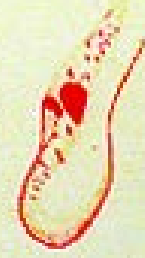

60

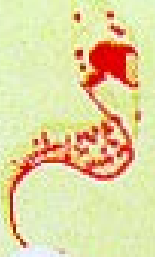

15

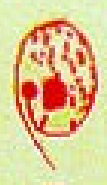

70
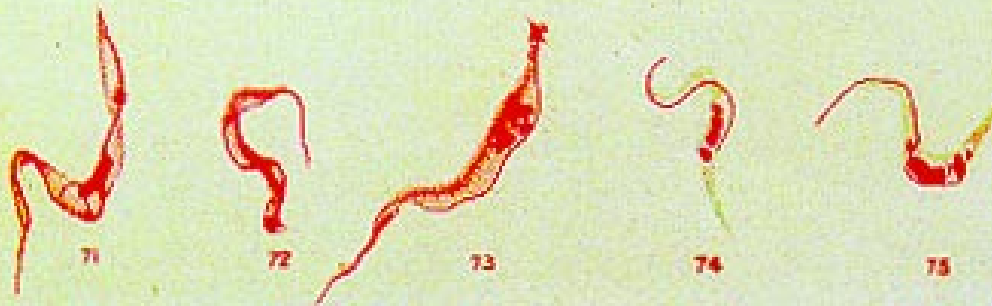

Fig. 1: schematic drawings taken from the original work of Chagas (1909), showing forms of Trypanosoma cruzi observed in the blood, in cultures and in the insect. Typical structures such as the nucleus, the kinetoplast and the flagellum are observed. However granular cytoplasmic structures are indicated in some illustrations such as those in figures 64 to 70 . Most of them may correspond to the acidocalcisomes only recently characterized in trypanosomatids. All illustrations are from the paper by Carlos Chagas published in the first issue of the Memórias do Instituto Oswaldo Cruz.
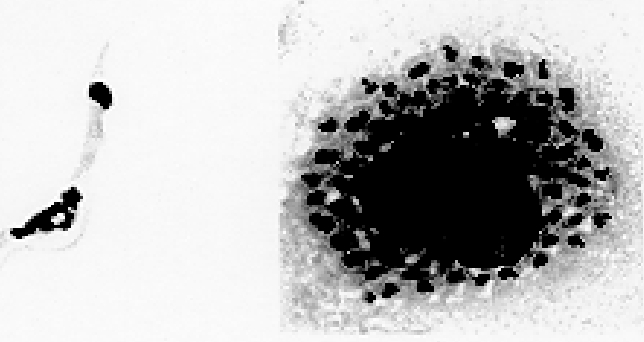

\section{Epimastigote}

\section{Trypomastigote}

Amastigote

Fig. 2: micrographs taken from developmental stages of Trypanosoma cruzi fixed in methanol and stained with Giemsa. 




Fig. 3: electron micrograph of the whole epimastigote form of Trypanosoma cruzi dried on the grid. It was obtained by $\mathrm{H}$ Meyer and KR Porter and published in 1954. No information was obtained in the central portion of the cell, However, fibrilar structures were seen at the periphery (arrow). X 10,000.

acidocalcisomeas and the reservosomes, which could be easily distinguished when spectroscopic images of cells previously incubated in the presence of gold-labeled proteins were obtained (Figs 5-7).

\section{THE EXAMINATION OF THIN SECTIONS}

Only in 1945, with the introduction of metachrylate resins (Newman et al. 1945) and the design of the first ultramicrotome at the Rockefeller Institute in New York, it was possible to obtain thin sections of cells. At that time osmium tetroxide was the fixative used to preserve the cells. Using these techniques Meyer (1958) obtained images which showed for the first time some important information. It became clear that what was known as the blepharoplast could be separated into three distinct structures. The first was the basal body from which the flagellum emerges. The second was the presence of a filamentous structure, whose morphology differs between epimastigote and trypomastigote forms (at that time known as crithidia and trypanosome forms, respectively), now known as the kinetoplast. The third was that the filamentous structure was located within the mitochondrion.

The introduction of (a) glutaraldehyde as an excellent fixative in 1959 (Sabatini et al. 1960), (b) epoxi resins for embedding of biological samples (Luft 1961), (c) modern ultramicrotomes and the use of diamond knives which allow the easy obtaintion of very thin sections (Fernandez Moran 1953), (d) new substances which enhance the contrast of the sections, such as lead citrate (Reynolds 1963) and uranyl acetate (Watson 1958), and (e) the development of new microscopes with better resolution, opened the possibility to analyze further the fine structure of the various developmental stages of the life cycle of $T$. cruzi and other trypanosomatids.

In the last 25 years a significant number of techniques were developed, all of them trying (a) to improve the preservation of macromolecules that form the biological structures, (b) to identify the chemical nature of the components observed, and (b) to develop new ways to prepare the samples so that high resolution analysis could be performed. The conjugation of these three objectives led to the development of a large number of techniques some of which have been successfully applied to the study of trypanosomatids. In the following sections I will summarize the most important information obtained on the fine structure of $T$. cruzi based on the examination of cells prepared using different techniques. Fig. 8 shows a general drawing of the epimastigote form of $T$. cruzi where most of the structures can be identified. Figs 9 and 10 show images of thin sections of epimastigote and amastigote forms, respectively, where most of the structures indicated in Fig. 8 can be recognized. 


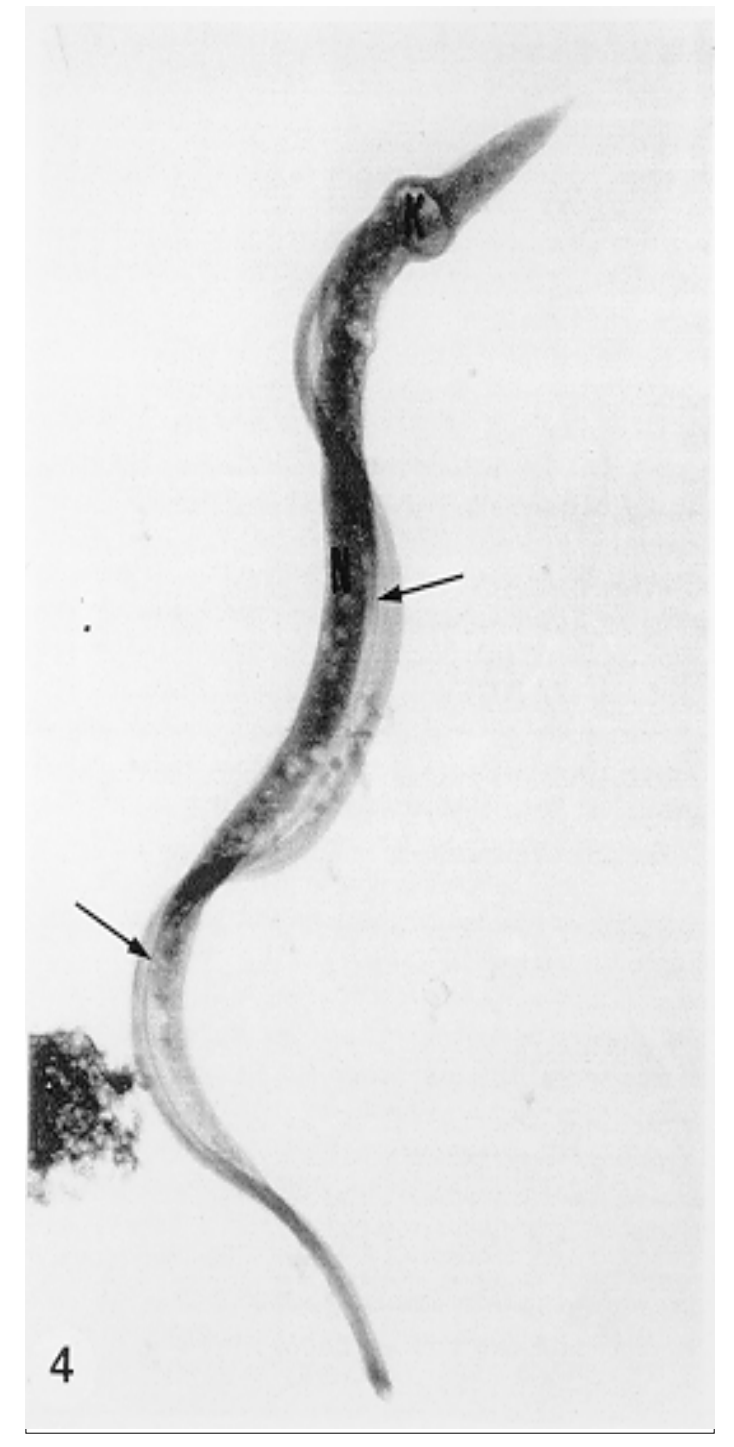

Fig. 4: high voltage electron microscopy of the whole trypomastigote form of Trypanosoma cruzi where structures such as the kinetoplast $(\mathrm{K})$, the nucleus $(\mathrm{N})$ and areas of adhesion of the flagellum to the cell body (arrows) can be seen. X 12,000 .

\section{THE CELL SURFACE}

From the morphological point of view the cell surface of trypanosomatids can be considered as composed of three structures: the glycocalix, the lipid bilayer, and the sub-pellicular microtubules.

The glycocalix of $T$. cruzi appears as a coat which is very thin in epimastigotes and amastigotes (Fig. 11) and a little thicker in trypomastigotes (Fig. 12). It is more evident when the cells are fixed in solutions containing ruthenium red or alcian blue. Its three-dimensional organization is better revealed in replicas of cells submitted to the fracture flip technique (Pimenta et al. 1989) (Figs 13-14) or in deep etched surfaces (Fig. 15). The use of labeled lectins have shown that glycoconjugates are uniformly distributed throughout the surface of the cell body and the flagellum. However, there is a concentration of lectin binding sites in the region around the cytostome (Fig. 14).

The lipid bilayer is better visualized in replicas of cells submitted to the conventional freeze-fracture technique. It is evident that there are more intramembranous particles, which correspond to integral membrane proteins, in the membrane lining epimastigotes than in the amastigote and trypomastigote forms. Although the particles are uniformly distributed throughout most of the plasma membrane (Figs 17, 19) there are a few areas of membrane specialization. The first, and more evident, is the cytostome found only in epimastigote and amastigote forms. It appears as an area with very few or no particles delimited by a palisade-like array of particles (Fig. 16). The second area is localized at the basis of the flagellum where a flagellar necklace is observed (Figs 1718). The third area is that involved in the attachment of the flagellum to the cell body. In general the flagellar membrane presents a much lower density of membrane particles than that lining the cell body (Fig. 20). However, a linear array of particles is observed at the flagellar-cell body attachment zone (Figs 20-22). Sterols, which can be visualized in replicas of cells incubated in the presence of the polyenic antibiotic filipin, is uniformly distributed (Souto-Padron \& De Souza 1983) throughout the membrane (Figs 23-25).

The cytoskeleton of trypanosomatids is basically formed by a layer of microtubules located below the plasma membrane. Studies carried out in replica of quick frozen, freeze-fractured, deepetched and rotary replicated cells show that small bridges connect the microtubules to each other, to the plasma membrane and to cisternae of the endoplasmic reticulum (Fig. 26). We still do not have precise information on the nature of the proteins which make these bridges.

\section{THE ENDOCYTIC PATHWAY}

It has been recognized that epimastigote forms of $T$. cruzi are able to ingest a large number of macromolecules. The available data indicate that this is a highly polarized process which takes place in the flagellar pocket region, and more efficiently in the cytostome (Soares \& De Souza 1991, Soares et al. 1992). This structure appears as a depression of the cell surface, followed by the sub-pellicular microtubules (Fig. 27). It originates in the anterior 

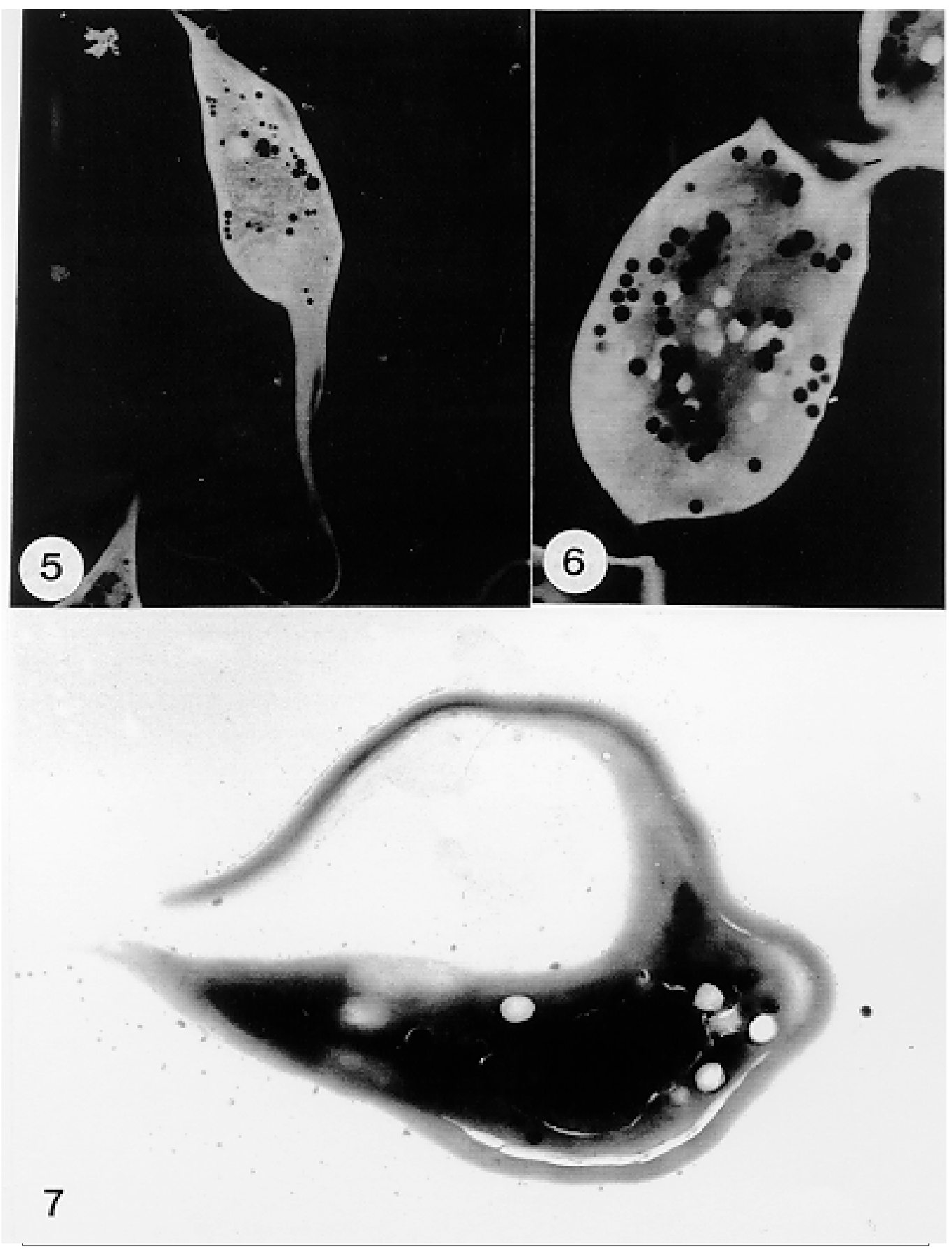

Figs 5-7: whole cells (epimastigote, amastigote and trypomastigote forms, respectively) examined with the transmission electron microscope. Figs 5 and 6 are spectroscopic images. The acidocalcisomes are clearly visualized as electron dense structures. Micrographs from Kildere Miranda, Marlene Benchimol, and Wanderley de Souza. Fig. 5: X 6,000; Figs 6-7: X 10,000.

portion of the cell and projects towards the posterior region, reaching the nucleus. As previously commented, freeze-fracture studies show that the membrane lining the cytostome is different from that lining other regions of the cell surface (Martinez-Palomo et al. 1976) (Fig. 16). Using the fracture flip technique it has been shown that it presents a rugous surface, probably due to the ex- 


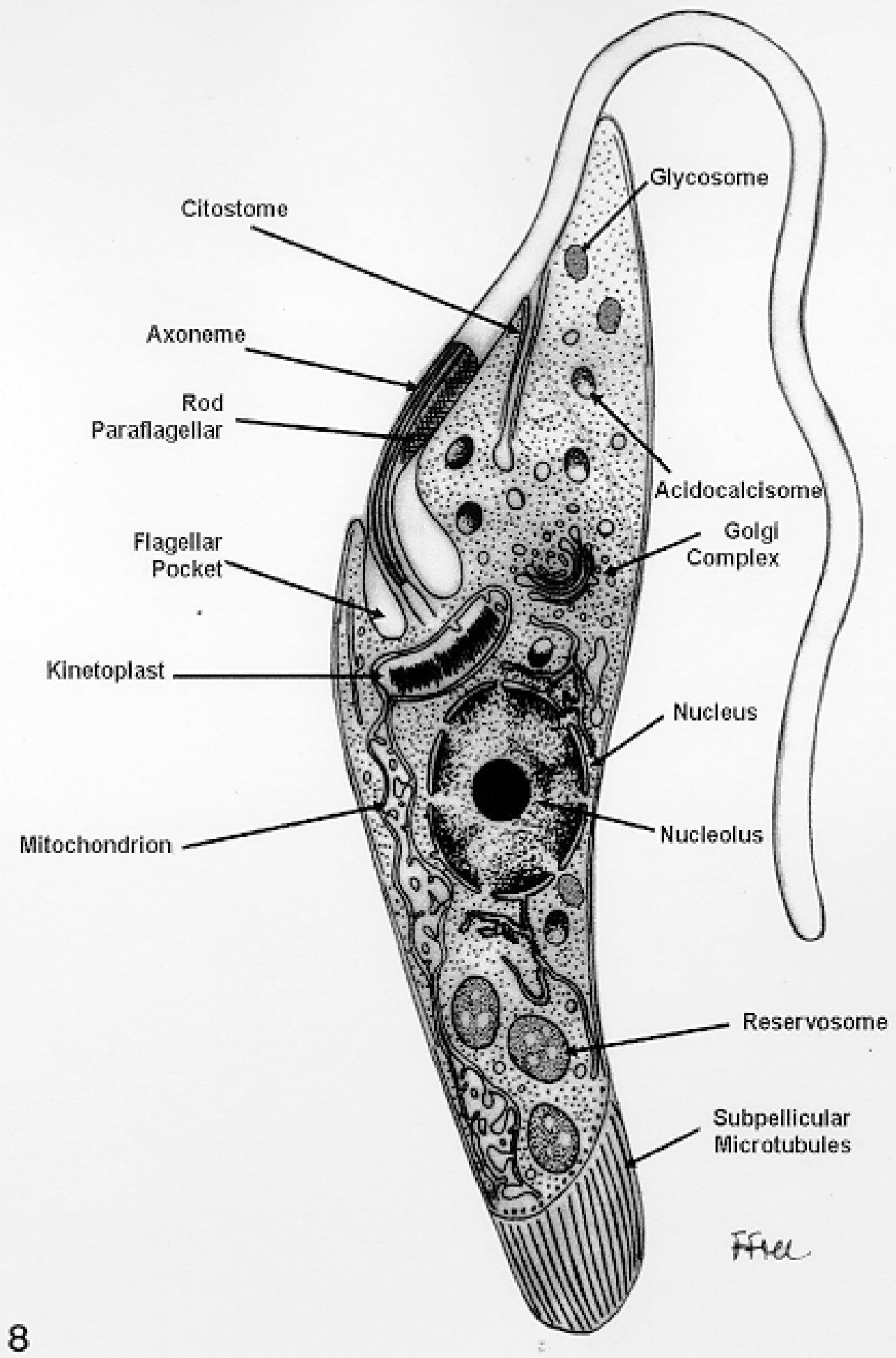

Fig. 8: schematic drawing, based on information obtained with the transmission electron microscope, showing the various structures found in the epimastigote form of Trypanosoma cruzi. 




Fig. 9: transmission electron microscopy of a thin section of the epimastigote form of Trypanosoma cruzi. Structures such as the flagellum (F), cell body (C), cytostome (Cy) and the kinetoplast (K) are indicated. X 60,000 


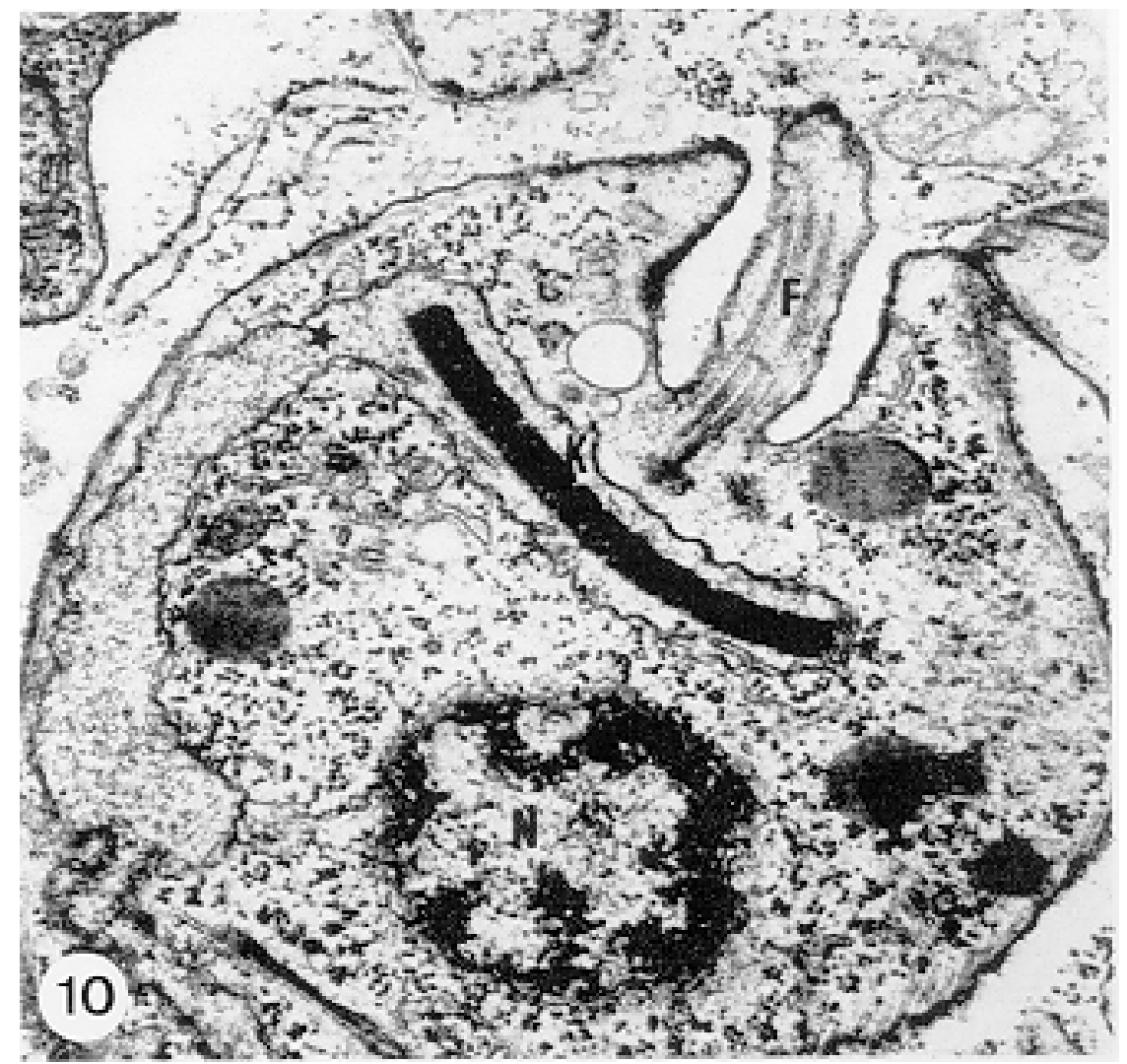

Fig. 10: transmission electron microscopy of a thin section of the intracellular amastigote (spheromastigote) form of Trypanosoma cruzi where it is evident that the kinetoplast $(\mathrm{K})$ is located within a ramified mitochondrion (star). A short flagellum $(\mathrm{F})$ and the nucleus (N) are also observed. X 30,000.

position of a large number of binding sites for lectins, receptor proteins for various ligands, etc. (Pimenta et al. 1989). Small endocytic vesicles originate at the cytostome, form long tubules and fuse with a special organelle located at the posterior region, known as reservosome (Figs 28-29). This organelle has been characterized in some detail and showed to correspond to a pre-lysosomal compartment. The available data suggest that the reservosome is the site of storage of ingested macromolecules which may be used during the process of transformation of epimastigote into trypomastigote forms.

\section{THE FLAGELLUM}

The flagellum of the trypanosomatids is involved in at least two important biological processes: movement of the cell, and attachment of the protozoan to the surface of cells from the vertebrate host and the perimicrovillar membranes lining the intestine of the invertebrate host. The characteristic features of the flagellar membrane was described above. Here I will emphasize the pres- ence in $T$. cruzi, and in other members of the Trypanosomatidae family, of a special structure known as the paraxial structure or the paraflagellar body. It is formed by a complex array of filamentous structures which are associated, through proteic bridges, to doublets number 4 to 7 of the axoneme (Farina et al. 1986). The fine structure of this structure was better shown in replicas of quick frozen, freeze-fractured, deep-etched and rotary replicated cells (Fig. 30). Biochemical studies have shown that that paraxial structure is formed by two major proteins of 71-80 and 68-73 $\mathrm{kDa}$ (reviews in Bastin et al. 1996, 1998). More recently this structure was isolated and additional minor proteins were identified (Moreira-Leite at al. in press). However, we still do not know which proteins make each of the filamentous structure observed.

\section{THE KINETOPLAST-MITOCHONDRION COMPLEX}

The kinetoplast corresponds to a condensation of extranuclear DNA within a well-defined region of the mitochondrion, forming a rounded or rodlike structure below the basis of the flagellum. The 


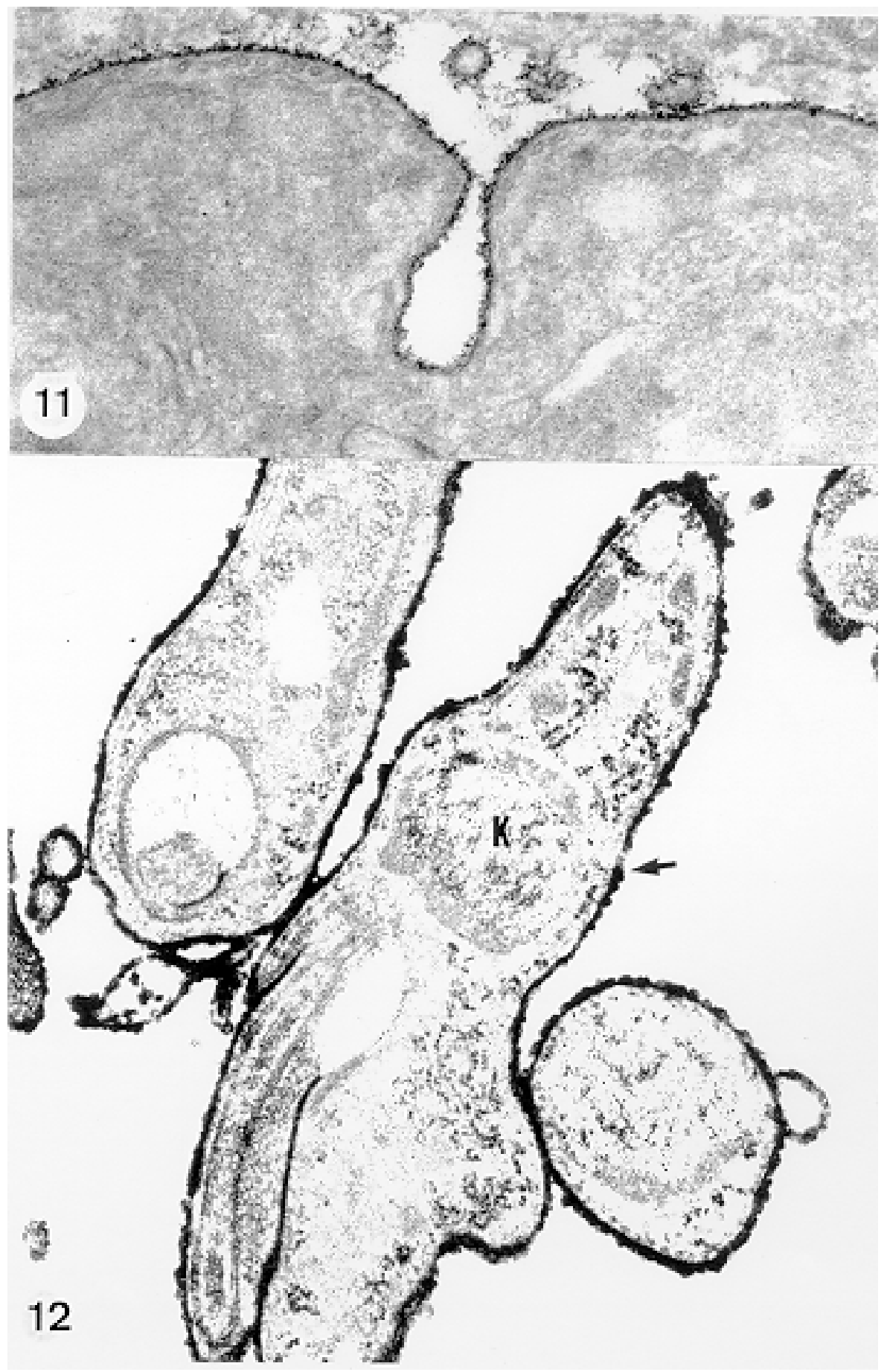

Figs 11-12: localization of sugar-containing molecules on the surface of amastigote (Fig. 11) and trypomastigote (Fig. 12) forms of Trypanosoma cruzi. A thin reactive layer is observed in amastigotes submitted to treatment with periodic acid, thiosemicarbazide and silver proteinate (Fig. 11). A thicker reactive layer is observed on the surface of trypomastigotes incubated with concanavalin A-peroxidase (arrow in Fig. 12). Fig. 11: X 45,000; Fig. 12: X 23,000. 

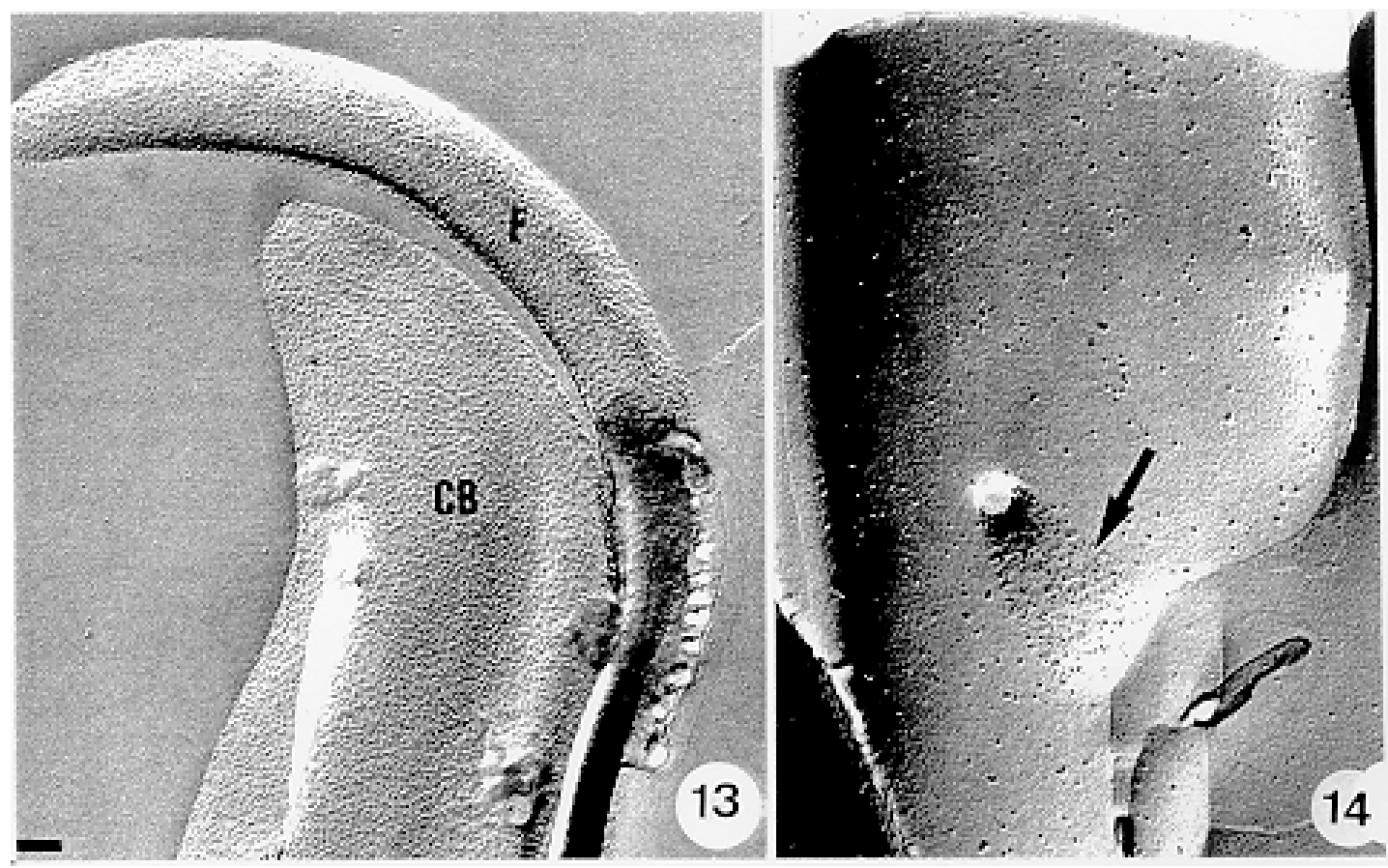

Fig. 13: trypomastigote form submitted to the fracture flip technique, revealing the surface projections of the membrane lining the cell body (CB) and the flagellum (F) (after Pimenta et al. 1989). X 30,000. Fig. 14: replica of an epimastigote form of $T$. cruzi incubated in the presence of gold-labeled concanavalin A. Intense labeling of the region lining the cytostome (arrow) is observed (after Pimenta et al. 1989). X 90,000.

kinetoplast DNA (K-DNA) may accounts for about $30 \%$ of the total cell DNA. The structure of the kinetoplast has been studied mainly in preparations of isolated kinetoplast networks shadowed at low angles with platinum-palladium. It is basically formed by a network of about 20,000 to 30,000 closely associated minicircles (Fig. 31). In addition to minicircles, the K-DNA also presents maxicircles with a length of 6 to $11 \mu \mathrm{m}$, which correspond to the well-known mitochondrial DNA found in all eukaryotic cells. Each minicircle has a length of about $0.45 \mu \mathrm{m}$, corresponding to 1440 base pairs and a molecular weight of $0,94.10^{6}$ (Englund et al. 1996). Analysis of the minicircle DNA following treatment with restriction enzymes has shown that the minicircles DNA are highly heterogeneous in sequence, making it possible to distinguish different stocks, strains, and clones within a species. The minicircle DNA codes for small guide RNAs that control the specificity of the process of editing of the mRNA formed from the maxicircles (Hadjuk \& Sabatini 1996).

The morphology of the kinetoplast, as seen in thin sections, varies according to the developmental stage. In epimastigotes and amastigotes it appears as a rod-like structure where the K-DNA is compactly organized (Figs 9-10). In trypomastigotes it is a rounded or basket-like structure with a more dispersed organization of the K-DNA (Figs 4, 12). Basic proteins can be identified in the kinetoplast of cells submitted to the ethanolic phosphotungstic acid and the ammoniacal silver techniques (Souto-Padron \& De Souza 1978).

\section{THE GLYCOSOME}

The glycosome is an organelle that may be rounded, with a diameter of $0.3 \mu \mathrm{m}$, or elongated, reaching a length of $2.8 \mu \mathrm{m}$, as observed in Leptomonas samueli. It belongs to the peroxisome group, presenting catalase in some species, and enzymes involved in the oxidation of amino acids and lipids (review in Opperdoes \& Michels 1991). One characteristic feature of this organelle is to concentrate and to compartmentalize the enzymes involved in the glycolytic pathway, increasing the efficiency of this process. In other cells these enzymes are localized in the cytoplasm matrix.

\section{THE ACIDOCALCISOME}

The presence of a membrane-bounded organelle with an empty space and an electrondense material located at the periphery has been described in several trypanosomatids as inclusion vesicles, volutin 


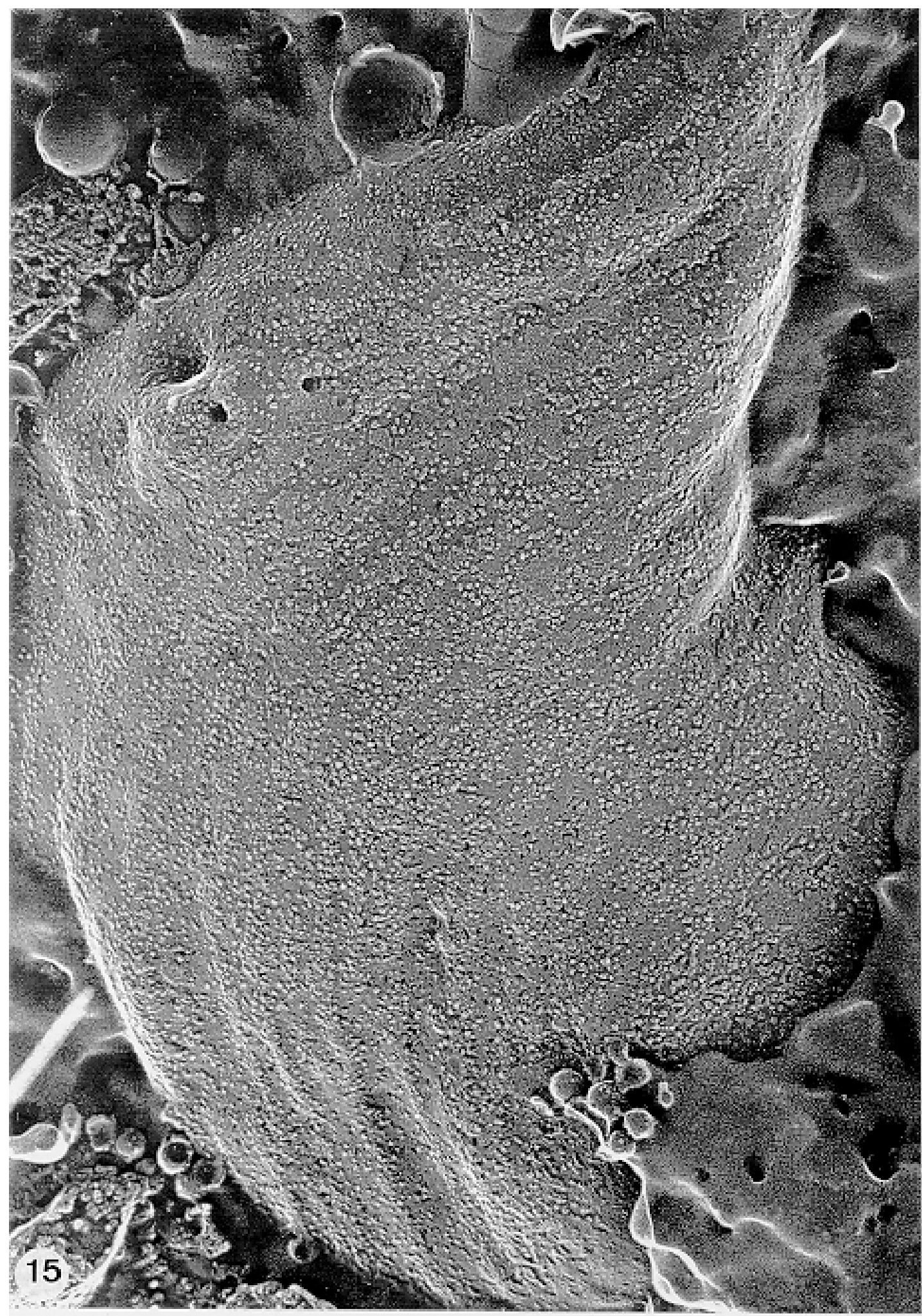

Fig. 15: general view of the surface of the epimastigote form as revealed using deep etching. A large number of surface proteins project out of the surface. X 120,000 . 


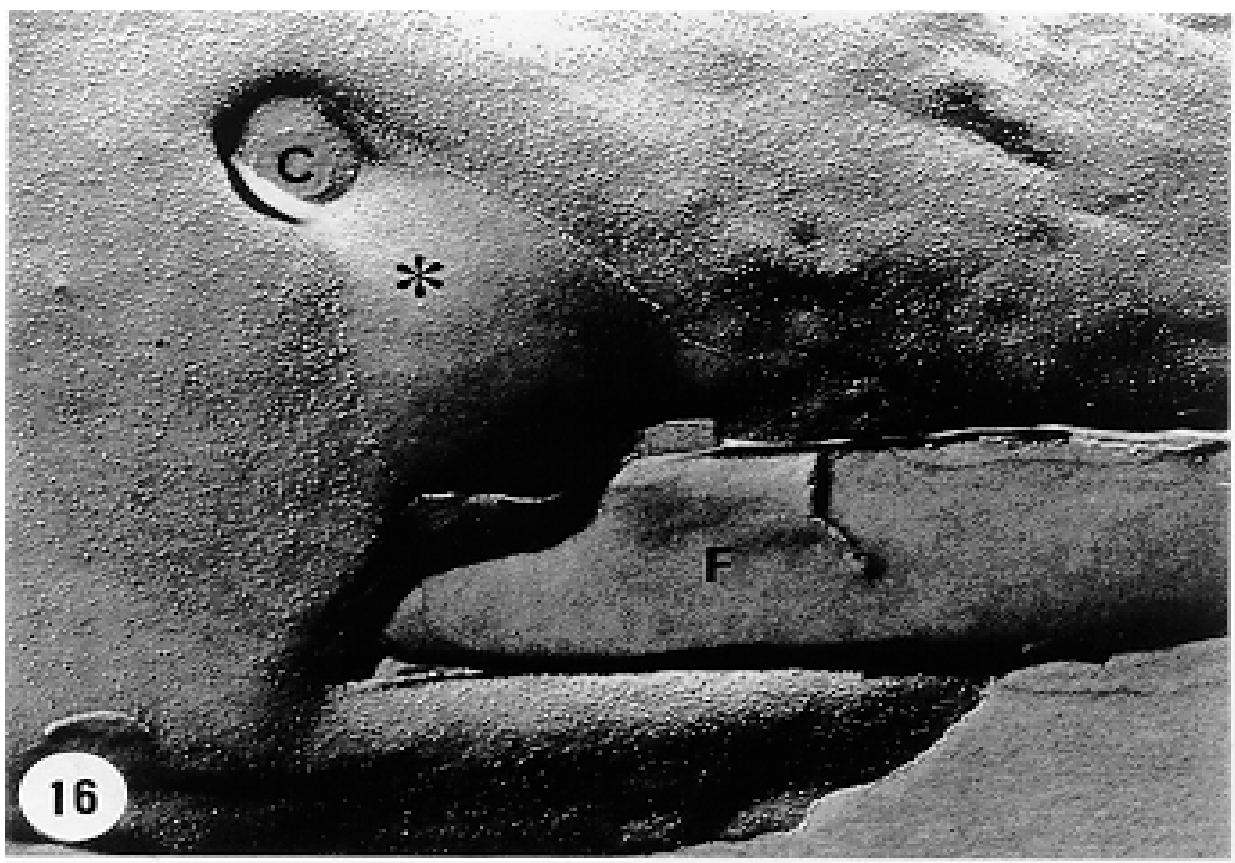

Fig. 16: freeze-fracture view of the region of emergence of the flagellum $(F)$ from the flagellar pocket of the epimastigote form. The cytostome (asterisk) appears as a fracture face free of intramembranous particles, with a clear opening (C). Very few membrane particles are observed on the fracture face of the flagellar membrane in contrast with the high density of particles of the membrane lining the cell body (after Martinez-Palomo et al. 1976). X 45,000.

granules, etc. More recently physiological studies have shown that $T$. cruzi, and other members of the Trypanosomatidae family, present a special acidic organelle which concentrates calcium (Docampo et al. 1995). Further morphological studies have shown clearly that the organelle previously described as volutin granules correspond to the acidocalcisome (Lu et al. 1998). Immunocytochemical studies have shown the presence of a vacuolar $\mathrm{H}^{+}$-ATPase, a $\mathrm{Ca}^{2+}$-ATPase and a Pyrophosphatase in the membrane lining the acidocalcisome (Benchimol et al. 1998, Scott et al. 1998). This organelle can be easily recognized, due to its intrinsic electrondensity, in whole cells examined in the transmission electron microscope (Figs 5-7). X-ray microanalysis studies confirmed the accumulation of calcium and phosphorous within the acidocalcisome (Scott et al. 1997). Morphometrical studies have shown that the number of acidocalcisomes varies according to the protozoan cell cycle.

\section{THE NUCLEUS}

The nucleus of trypanosomatids has not been investigated in detail. Using transmission electron microscopy of thin sections it has been shown that interphasic cells present chromatin mainly localized at the nuclear periphery and a centrally located nucleolus. At the beginning of division the chromatin disperses and the nucleolus disappear, leaving the nucleus with a homogeneous and less dense appearance. However, microtubules and small dense plates appear during mitosis. The nuclear membrane remains intact during the whole cell division process. The number of plates varies according to the trypanosomatid species. In the case of T. cruzi 10 plates were observed (Solari 1980).

\section{OTHER STRUCTURES}

A number of other structures such as ribosomes, endoplasmic reticulum, Golgi complex, and vacuoles are observed in T. cruzi. However, they either do not present any characteristic feature or have not been studied in detail. Therefore, are not commented in this short review.

\section{REFERENCES}

Bastin P, Mathews KR, Gull K 1996. The paraflagellar rod of Kinetoplastida: solved and unsolved questions. Parasitol Today 12: 302-307.

Bastin P, Sherwin T, Gull K 1998. Paraflagellar rod is vital for trypanosome motility. Nature 391: 548.

Benchimol M, De Souza W, Vanderheydens N, Zhong L, Lu HG, Moreno SNJ, Docampo R 1998. Functional expression of a vacuolar-type H-ATPase in the plasma membrane and intracellular vacuoles of Trypanosoma cruzi. Biochem J 332: 695-702. 


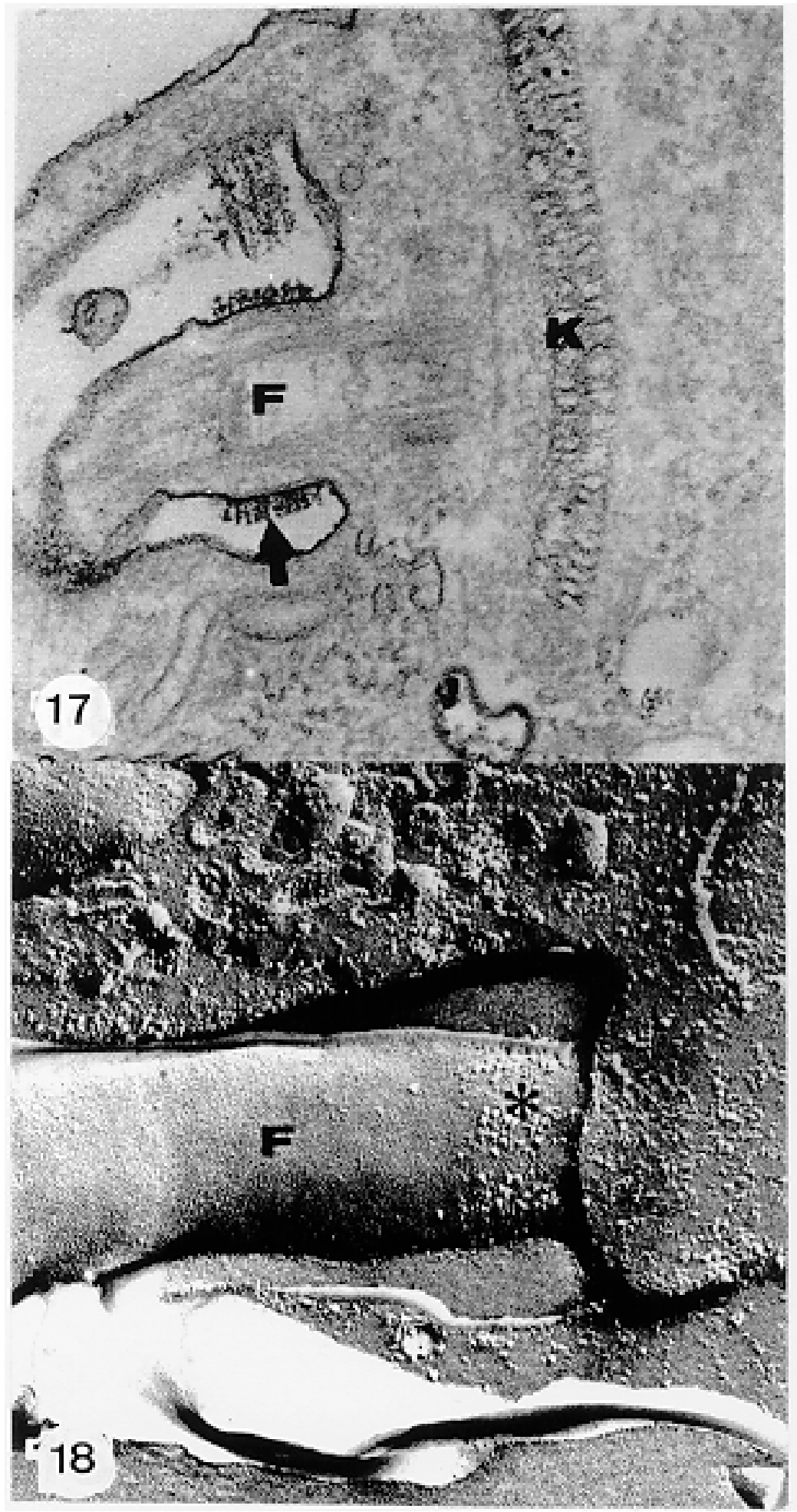

Figs 17-18: the basal region of the flagellum presents a specialized area that can be revealed either as surface projections in cells stained with ruthenium red (arrow in Fig. 17) or as aggregates of particles on the membrane fracture face (asterisk in Fig. 18). F, flagellum; K, kinetoplast (after De Souza et al. 1978). Fig. 17: X 60,000; Fig. 18: X 100,000. 


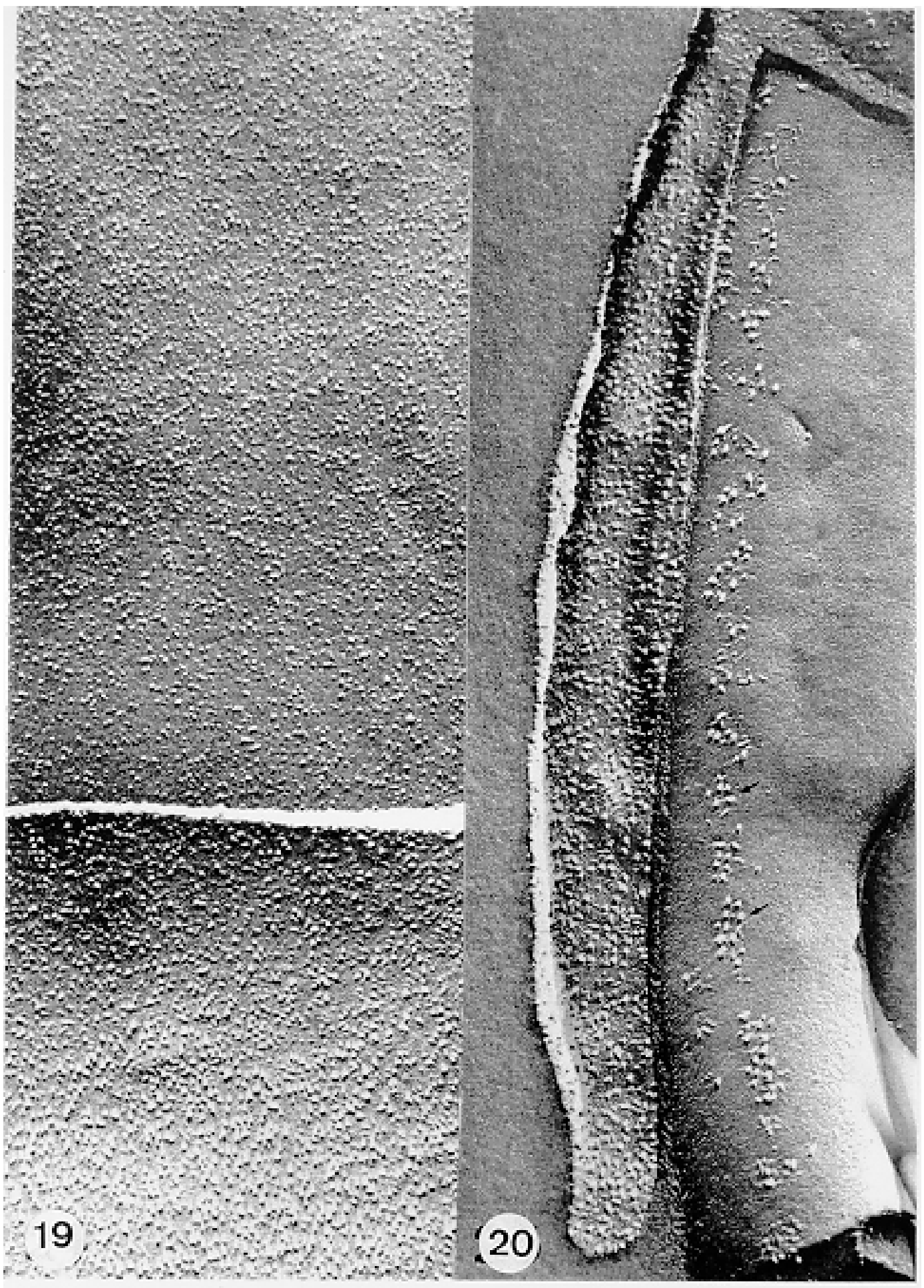

Figs 19-20: freeze-fracture view of the protoplasmic and extracellular fracture faces of the membrane lining the cell body (Fig. 19) and the region of attachment of the flagellum to the cell body of the epimastigote form (Fig. 20). A special array of particles is observed in the region of adhesion (small arrows in Fig. 20). Fig. 19: X 100,000; Fig. 20: X 150,000. 


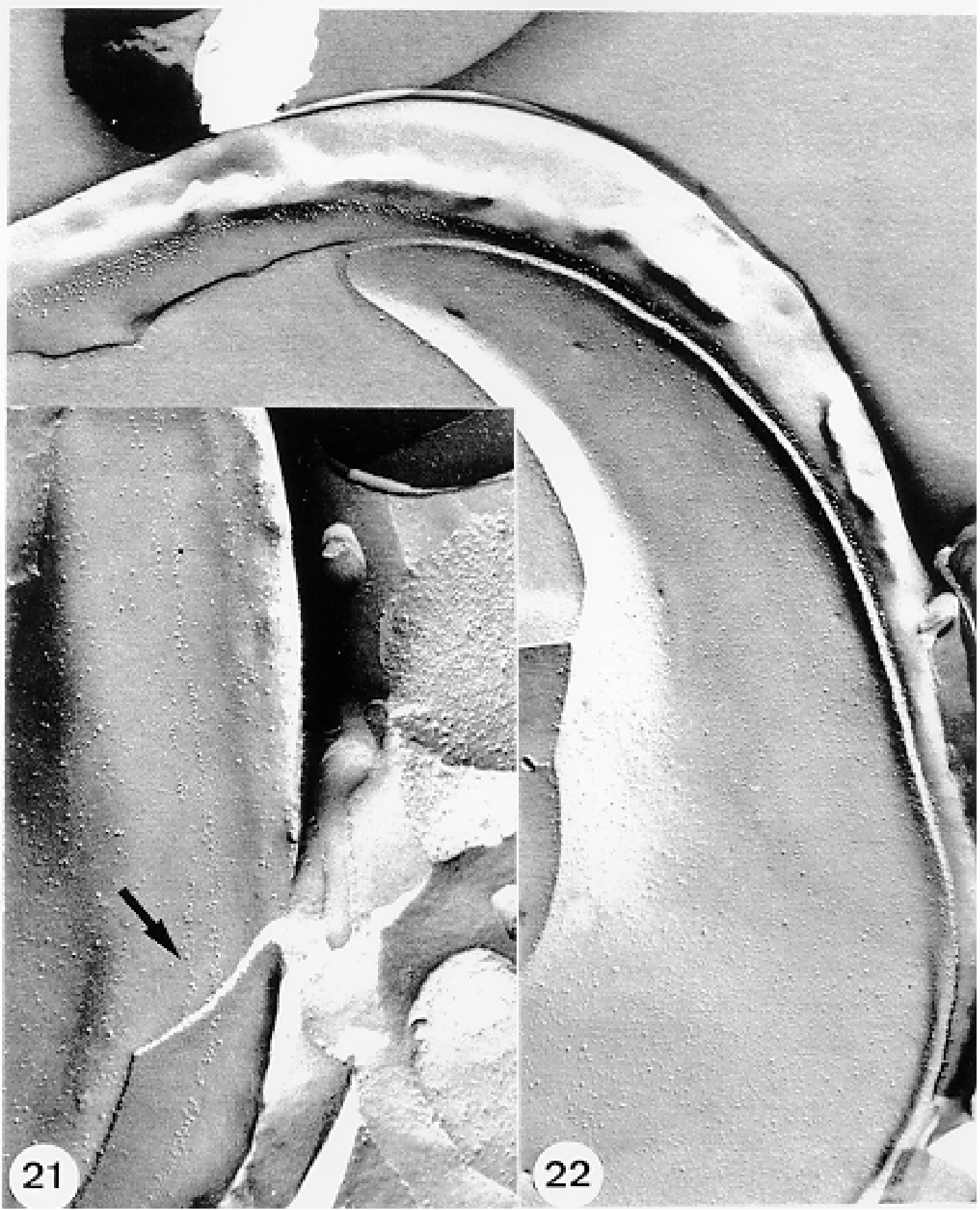

Figs 21-22: fracture faces of the region of attachment of the flagellum to the cell body of the trypomastigote form. A special array of particles is observed in the fracture face of the membranes lining the cell body and the flagellum (arrow). Fig. 21: X 65,000; Fig. 22: X 40,000.

Chagas C 1909. Nova tripanosomiase humana. Estudos sobre a morfolojia e o ciclo evolutivo do Schizotrypanum cruzi, n.g., n. Sp., ajente etiolójico de nova entidade morbida do homem. Mem Inst Oswaldo Cruz 1: 159-218.

Docampo R, Scott DA, Vercesi AE, Moreno SN 1995.
Intracellular $\mathrm{Ca}^{2+}$ storage in acidocalcisomes of Trypanosoma cruzi. Biochem J 310: 1005-1012.

Englund P, Guilbride DL, Hwa K-Y, Johnson CE, Li C, Rocco LJ, Torri AF 1996. Kinetoplast DNA: structure and replication, p. 75-87. In DF Smith \& M Parsons (eds), Molecular Biology of Parasitic Pro- 


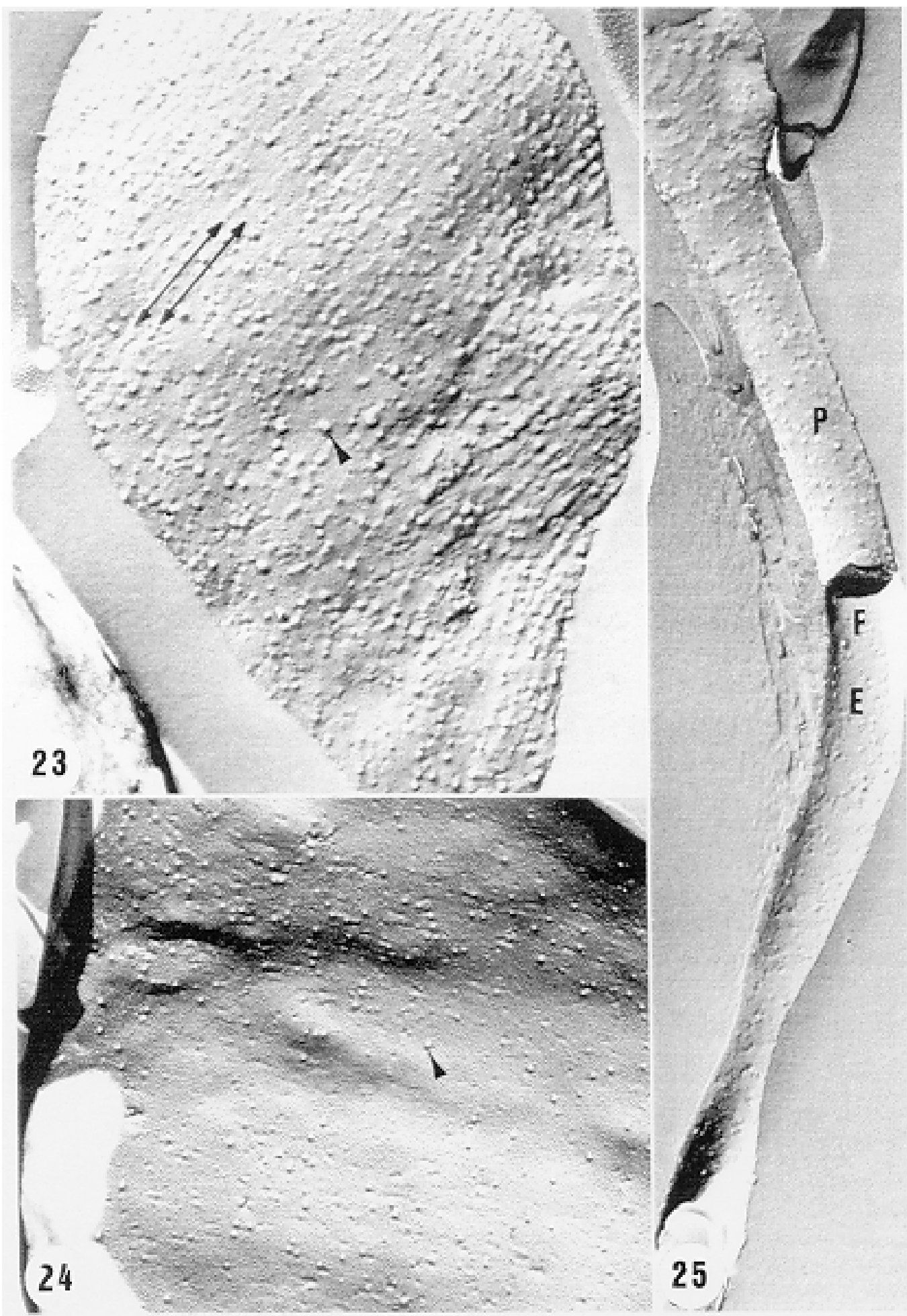

Fig. 23-25: freeze-fracture images of fracture faces of the plasma and flagellar membranes of epimastigotes treated with the polyenic antibiotic filipin. Filipin-sterol complex are indicated by the arrowheads. Arrows in Fig. 23 indicate the parallel array of the filipin-sterol complexes. F, flagellum; P and E refer to the protoplasmic and extracellular fracture faces, respectively (after Souto-Padron \& De Souza 1983). Figs 23, 24: X 35,000; Fig. 25: X 30,000. 




Fig. 26: deep-etching view of quick frozen and freeze-fractured cells exposing the sub-pellicular microtubules. Filamentous structures are seen connecting the microtubules to each other. X 90,000 .

tozoa, IRL Press, New York.

Farina M, Attias M, Souto-Padron T, De Souza W 1986.

Further studies on the organization of the paraxial rod of trypanosomatids. J Protozool 33: 552-557.

Fernandez-Moran H 1953. A diamond knife for ultrathin sectioning. Exp Cell Res 5: 255-259.

Hadjuk SL, Sabatini RS 1996. RNA editing: post-transcriptional restructuring of genetic information, p.134-158. In DF Smith \& M Parsons (eds), Molecular Biology of Parasitic Protozoa, IRL Press, 


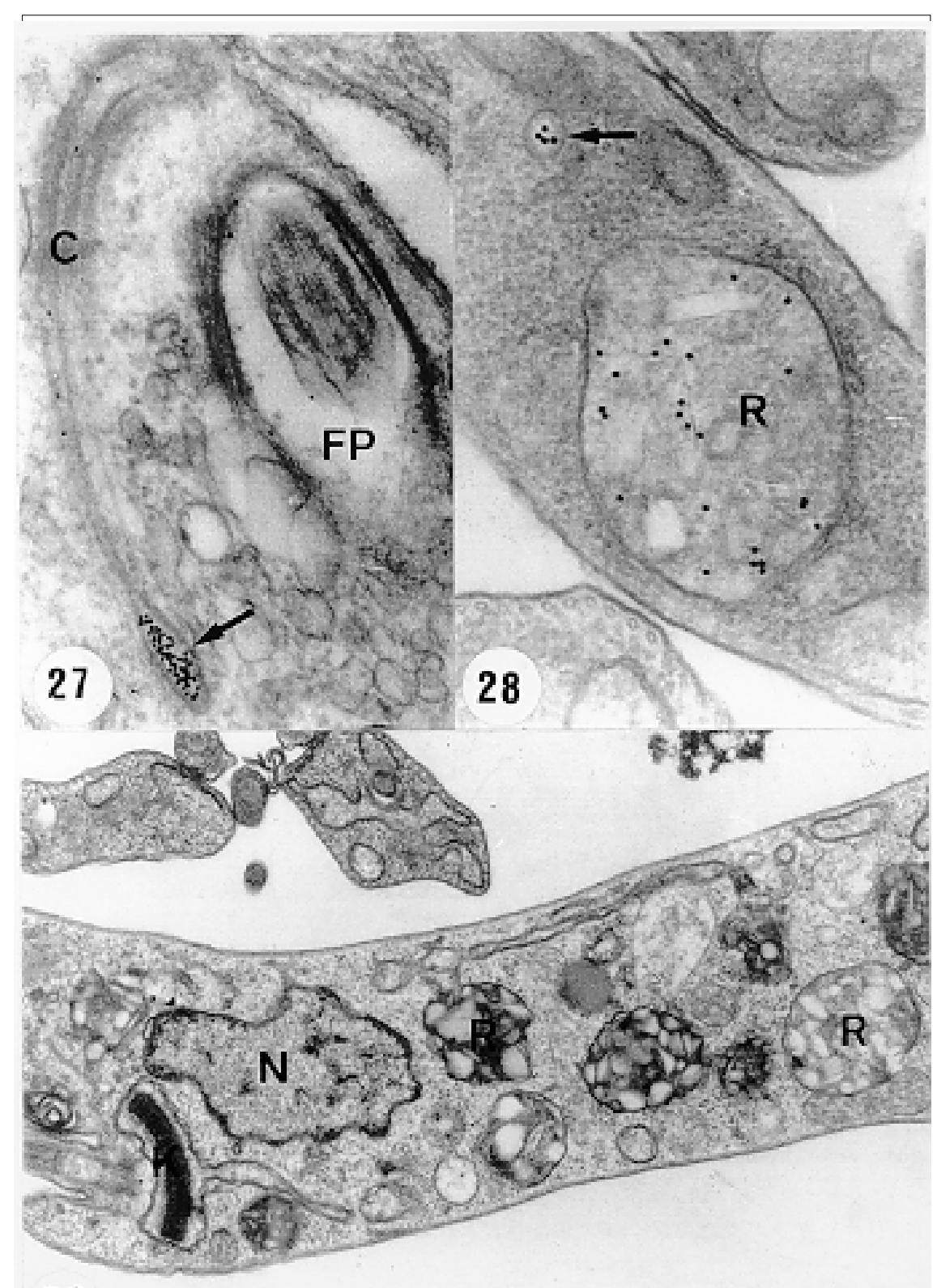

\section{9}

Figs 27-29: transmission electron microscopy of thin sections of epimastigote forms incubated in the presence of gold-labeled proteins. The probes are ingested through the cytostome $(\mathrm{C})$ and the flagellar pocket $(\mathrm{FP})$ and concentrate in cytoplasmic organelles known as reservosomes (R). K: kinetoplast; N: nucleus (after Soares \& De Souza 1991). Fig. 27: X 35,000; Fig. 28: X 50,000; Fig. 29: X 18,000.

New York.

Lu H-G, Zhong L, De Souza W, Benchimol M, Moreno SN, Docampo R 1998. $\mathrm{Ca}^{2+}$-content and expression of an acidocalcisomal calcium pump are elevated in intracellular forms of Trypanosoma cruzi. Mol Cell Biol 18: 2309-2323.

Luft J 1961. Improvements of epoxy resin embedding methods. J Biophys Biochem Cytol 9: 409-417.
Martinez-Palomo A, De Souza W, Gonzalez-Robles A 1976. Topographical differences in the distribution of surface coat components and intramembranous particles. J Cell Biol 69: 507-513.

Meyer H 1958. The fine structure of the flagellum and the kinetoplast-chondriome of Trypanosoma (Schizotrypanum) cruzi in tissue culture. J Protozool 15: 614-621. 


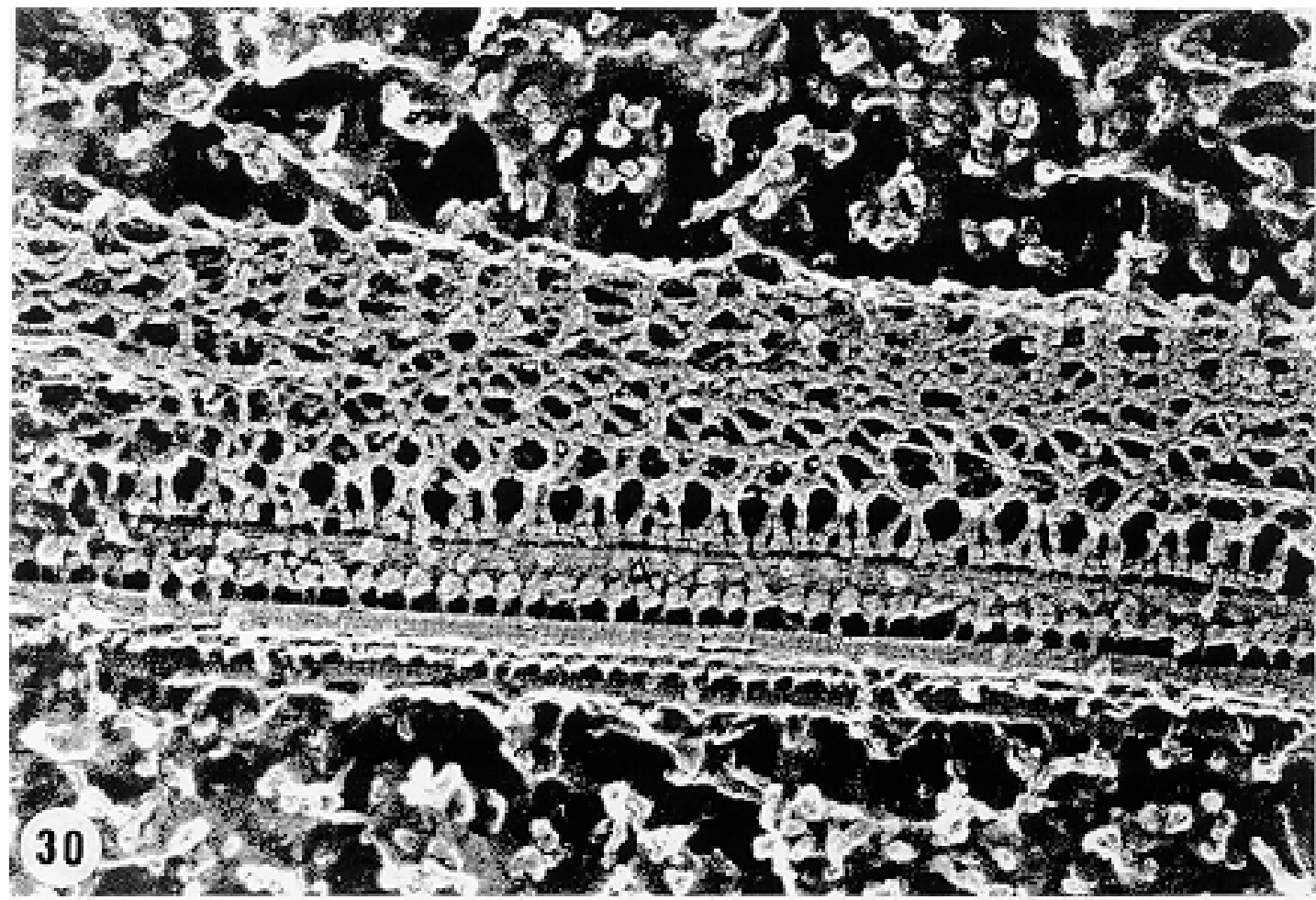

Fig. 30: deep-etched view of the flagellum where the axoneme (A) and a complex array of filaments which compose the paraxial structure can be observed (after Farina et al. 1986). X 140,000.

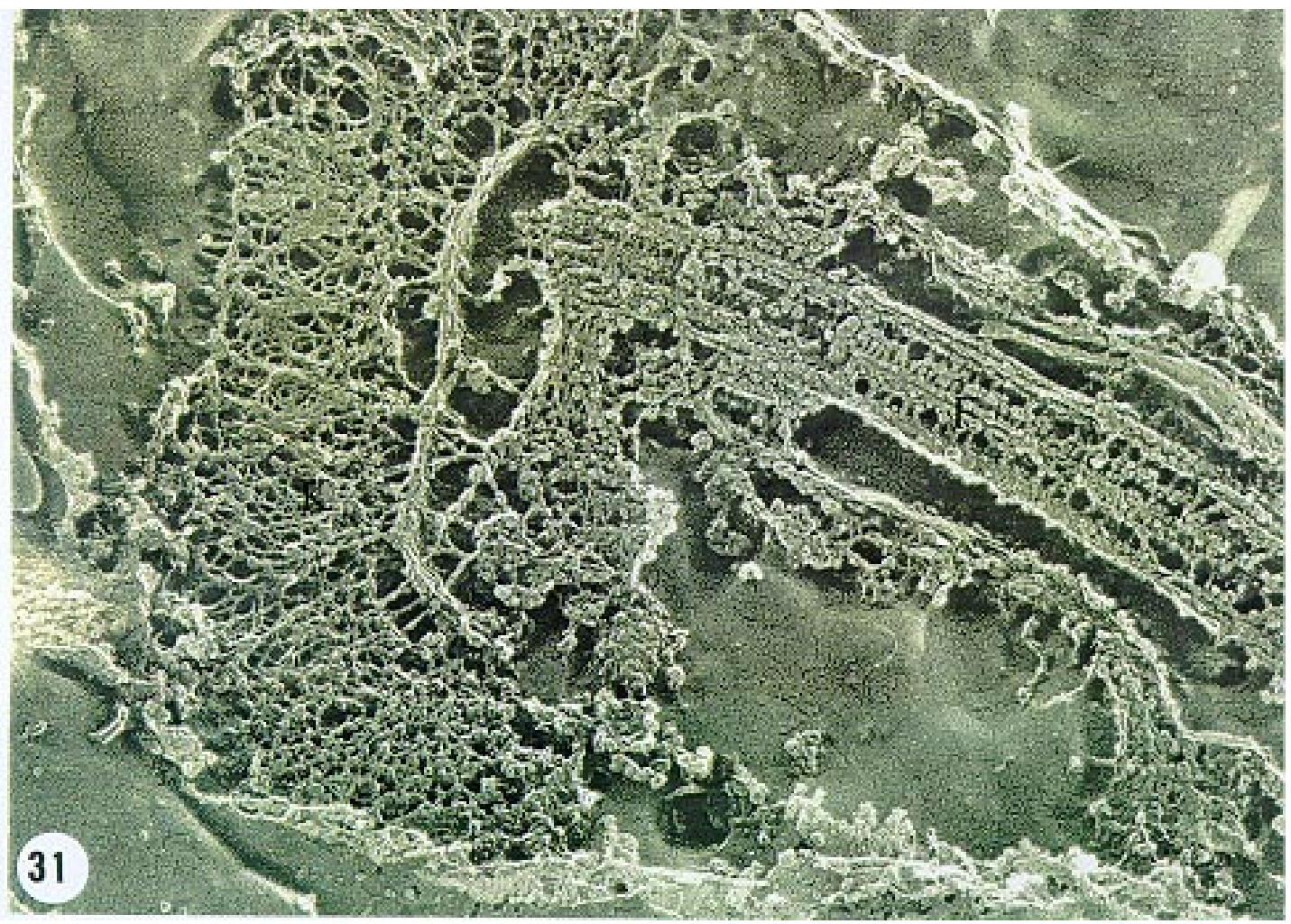

Fig. 31: deep-etch view of the kinetoplast and the emergence of the flagellum (F) of an epimastigote form. The kinetoplast (K) appears as a complex array of polygonal structures (after Souto-Padron et al. 1984). X 80,000. 
Meyer H, Porter KR 1954. A study of Trypanosoma cruzi with the electron microscope. Parasitology 44: 1-2.

Moreira-Leite FF, De Souza W, Cunha e Silva NL. Purification of the paraflagellar rod of the trypanosomatid Herpetomonas megaseliae and identification of some of its minor components. Mol Biochem Parasitol, in press.

Newman SB, Borysko E, Sweerdlown M 1945. New sectioning techniques for light and electron microscopy. Science 110: 66-69.

Opperdoes FR, Michels PAM 1991. The evolutionary origin of glycosomes. Parasitol Today 7: 105-109.

Pimenta PFP, De Souza W, Souto-Padron T, Pinto da Silva P 1989. The cell surface of Trypanosoma cruzi: a fracture flip, replica-staining label fracture survey. Eur J Cell Biol 50: 263-271.

Reynolds ES 1963. The use of lead citrate at high $\mathrm{pH}$ as an electron opaque stain in electron microscopy. $J$ Cell Biol 17: 208-212.

Riou G, Delain E 1969. Electron microscopy of of the circular kinetoplastic DNA from Trypanosoma cruzi: occurrence of catenated forms. Proc Natl Acad Sci USA 62: 210-217.

Sabatini D, Bensch K, Barrnett RJ 1960. Cytochemistry and electron microscopy. The preservation of cellular structures and enzymatic activity by aldehyde fixation. J Cell Biol 17: 19-32.

Scott DA, De Souza W, Benchimol M, Zhong L, Lu HG, Moreno SNJ, Docampo R 1998. Presence of a plantlike proton-pumping pyrophosphatase in acido- calcisomes of Trypanosoma cruzi. J Biol Chem 34: 22151-22158.

Scott DA, Docampo R, Dvorak JA, Shi S, Leapman RD 1997. In situ compositional analysis of acidocalcisomes in Trypanosoma cruzi. J Biol Chem 272: 28020-28029.

Soares MJ, De Souza W 1991. Endocytosis of gold-labeled proteins and LDL by Trypanosoma cruzi. Parasitol Res 77: 461-469.

Soares MJ, Souto-Padron T, De Souza W 1992. Identification of a large prelysosomal compartment in the pathogenic protozoan Trypanosoma cruzi.J Cell Sci 102: $157-167$.

Solari AJ 1980. The tree-dimensional structure of the mitotic spindle in Trypanosoma cruzi. Chromosoma 78: 239-249.

Souto-Padron T, De Souza W 1978. Ultrastructural localization of basic proteins in Trypanosoma cruzi. $J$ Histochem Cytochem 26: 349-358.

Souto-Padron T, De Souza W 1983. Freeze-fracture localization of filipin-cholesterol complexes in the plasma membrane of Trypanosoma cruzi. J Parasitol 69: 129-137.

Souto-Padrón T, De Souza W, Heuser JE 1984. Quickfreeze, deep-etched rotary replication of Trypanosoma cruzi and Herpetomonas megaseliae. J Cell Sci 69: 167-178.

Watson ML 1958. Staining of tissue sections for electron microscopy with heavy metals. J Biophys Biochem Cytol 4: 475-481. 